\title{
MÁS ALLÁ DE LA CRÍA EXTENSIVA: UN ESTUDIO MATIZADO SOBRE LA GEOGRAFÍA ECONÓMICA DE URUGUAY ANTES DE LA MODERNIZACIÓN*
}

\author{
Carolina Vicario \\ Universidad de la República, Montevideo, Uruguay, <cvicario@fcs.edu.uy>
}

\begin{abstract}
Resumen. Este artículo analiza algunas características sociodemográficas y económicas de las sociedades de América Latina precapitalistas del Cono Sur; específicamente, la estructura demográfica y ocupacional del sur de Uruguay entre 1760 y 1860. Se enfatiza en la importancia de la mano de obra familiar en los distintos contextos socioeconómicos de la región, así como en el peso de los sectores productivos en la estructura ocupacional. A partir de esto se visualiza una geografía económica distinta a la que planteaba a Uruguay como un territorio homogéneo: las regiones se distinguen según su trayectoria demográfica y económica y se matiza la imagen de una sociedad segmentada en estancieros y gauchos, característica de la historiografía tradicional de la cuenca del Plata. A partir de padrones de la población de Montevideo y sus alrededores se estudia el tamaño y la composición de los hogares, la población activa y la estructura ocupacional.
\end{abstract}

Palabras clave: economía precapitalista, Río de la Plata, demografía, estructura del empleo.

Abstract. The aim of this paper is to establish some questions about some economic and demographic characteristics of pre-industrial Latin America societies, specially the demographic and occupational structure of the South of Uruguay between 1760 and 1860 in the Río de la Plata context. We highlight in the first place the importance of the familiar labor force in different socioeconomic contexts of the region; in the second place, the size of the productive sectors in the occupational structure. From this, we can see a different economic geography from those which raised the image of Uruguay as a homogeneous territory: the regions are distinguished by the demographic and economic path and the society segmented in estancieros and gauchos is questioned. From population registers from Montevideo and surroundings we analyze the size and composition of the homes, the active population and the occupational structure.

Key words: pre-industrial economy, Río de la Plata, demography, occupational structure.

Fecha de recepción: septiembre de 2010. Fecha de aceptación: febrero de 2011

* Este artículo ha sido financiado con fondos de la Agencia Nacional de Investigación e Innovación en Uruguay.

Am. Lat. Hist. Econ., año 19, núm. 2 (38), mayo-agosto, 2012, pp. 73-106 


\section{INTRODUCCIÓN}

$\mathrm{E}$ ste artículo se inscribe en el estudio de las sociedades y economías preindustriales del sur de América Latina, específicamente en Río de la Plata. El problema de estudio es la caracterización sociodemográfica de estas sociedades en relación con el mercado de trabajo y la estructura ocupacional.

La dicotomía de sociedades modernas-tradicionales nació en la sociología clásica para caracterizar la transformación de las sociedades occidentales de base agraria en sociedades modernas, de base industrial, con todas sus transformaciones inherentes, pero tuvo una larga vida posterior en la sociología del siglo XX, en especial, durante la hegemonía del funcionalismo, así como en la economía del desarrollo de primera generación. ${ }^{1} \mathrm{El}$ alcance preciso de estos conceptos ha variado al punto de verse cuestionada su fuerza dicotómica.

En el caso de Uruguay, la tradición historiográfica ha aceptado de manera implícita la conceptualización clásica, introduciendo la noción de un intenso proceso de modernización económico, político y social entre 18601914. ${ }^{2}$ Así, antes habría existido, en primera instancia, una sociedad colonial tardía y otra pastoril y caudillesca, atravesadas ambas por rasgos productivos, tecnológicos y sociales propios de las sociedades tradicionales, ${ }^{3}$ mientras que la posterior a 1914 es una sociedad capitalista, que si bien no es intensamente industrial, es fuertemente urbana y de servicios. En este artículo se hace énfasis en las sociedades del periodo 1760-1860, es decir, en aquellas que en algunos casos se generaron, en otros se consolidaron y finalmente entraron en crisis, entre las reformas borbónicas de Río de la Plata y la consolidación de los Estados nacionales rioplatenses.

Para contextualizar el periodo y la región de análisis se partió de la hipótesis que sugiere la existencia de dos paisajes diferenciados en los comienzos del poblamiento del territorio que comprende las delimitaciones actuales de Uruguay: el sur-atlántico (delimitado por los ríos de la Plata, Uruguay y Yí, y la laguna Merín), y el norte-misionero (delimitado por el río Negro, Uruguay e Ibicuí, y la orilla atlántica de la laguna de los Patos). ${ }^{4}$ El mapa 1 muestra las dos regiones delimitadas por el río Negro.

La existencia de estos paisajes cuestiona tanto la concepción de homogeneidad del territorio desde el punto de vista económico y social, como la metodología de análisis histórica que delimita al territorio basándose

\footnotetext{
${ }^{1}$ Hettne, Development, 1990.

${ }^{2}$ Barrán y Nahum, Historia, 1971-1978, tt. II-VII, y Millot y Bertino, Historia, 1991.

${ }^{3}$ Pivel, Raíces, 1957; Sala de Touron et al, Evolución, 1967; Sala de Touron y Alonso, Estructura, 1991, y Millot y Bertino, Historia, 1996, t. II.

${ }^{4}$ Moraes, Pradera, 2008.
} 


\section{MAPA 1. CUENCA DEL RÍO DE LA PLATA ENTRE 1760 Y 1860}

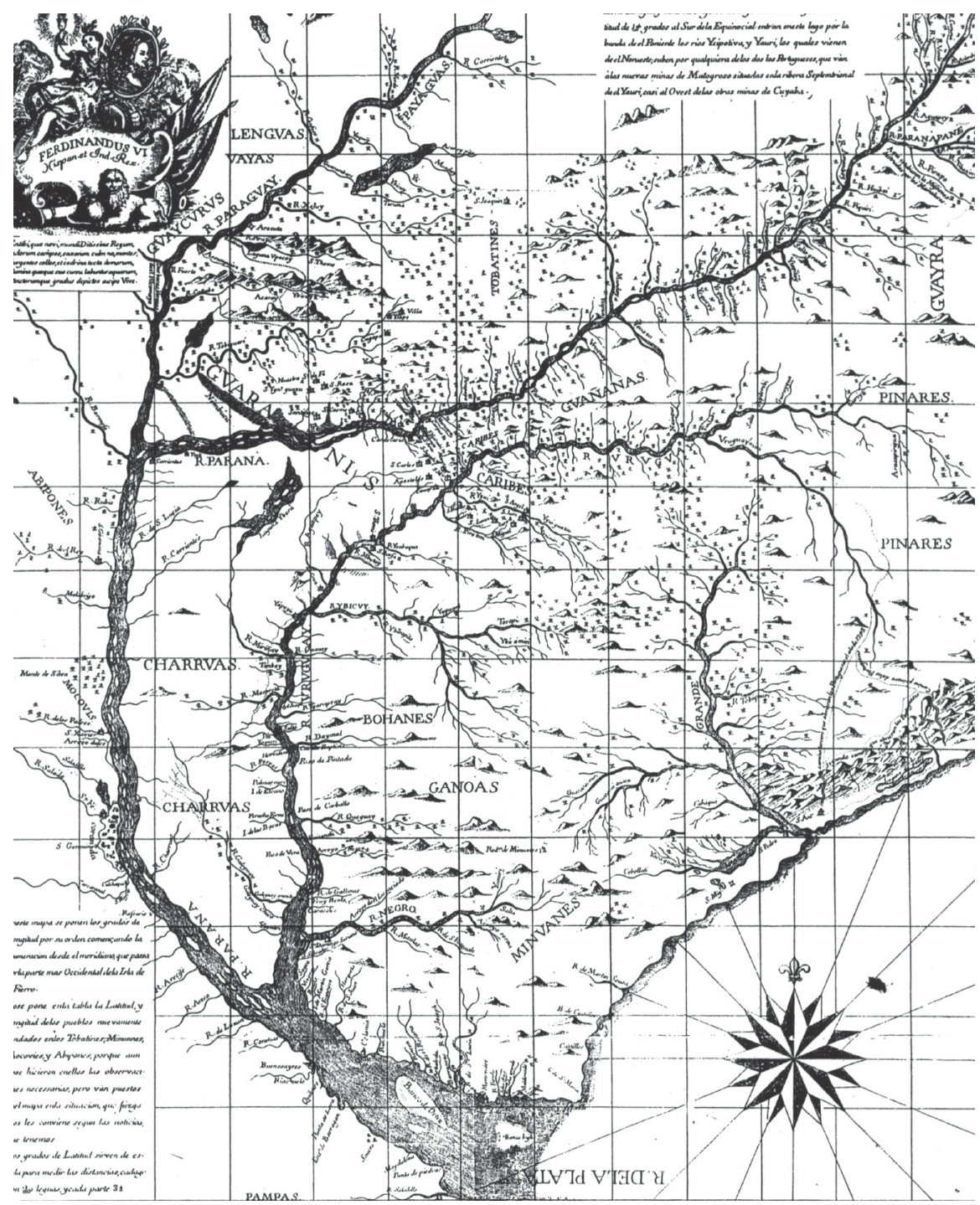

Fuente: Fragmento del Mapa de las misiones de la compañía de Jesús en los ríos Paraná y Uruguay, realizado por el padre José Quiroga en 1749, impreso en Roma en 1753 sobre un grabado de Ferdinando Franceschelli, en Maeder y Gutiérrez, Atlas, 1994. 
en las demarcaciones actuales. El punto de partida desde esta hipótesis pretende incluir el proyecto en una línea historiográfica revisionista de algunos procesos de la historia económica y social.

Según Moraes y Pollero, ${ }^{5}$ los territorios comprendidos al sur del río Negro durante el siglo XVII constituyeron una especie de segunda campaña de Buenos Aires, una frontera a conquistar tanto por parte de las autoridades como por inversionistas privados. Desde la fundación de la colonia de Sacramento por la corona portuguesa en 1680 se originó una contraofensiva por parte de la corona española sobre la franja marítima rioplatense. Se abrió entonces un ciclo de fundaciones que comenzó con la de Montevideo en la década de 1720 y que puede decirse que culminó con la de Batoví en 1801, en el territorio de las nacientes del río Negro. Cada villa y pueblo que se fundaba constituyó un foco de colonización blanca que desarrollaba un entorno productivo con un diverso acceso a los recursos según el origen de la ciudad y comenzaba un lento proceso de articulación con otros agentes del territorio, fueran nucleares o dispersos. ${ }^{6}$

Los temas que se pretenden analizar en este trabajo tienen dos focos principales: $a$ ) el de la caracterización sociodemográfica de las sociedades preindustriales latinoamericanas anteriores al auge agroexportador, y $b$ ) el de la composición de la mano de obra, es decir, la abundancia-escasez y la relación de la mano de obra libre con la esclava. En este sentido, resulta relevante conocer el tamaño de la población activa, la relación de esta con la mano de obra esclava en cada contexto y el peso de los sectores productivos en la estructura ocupacional.

Este trabajo pretende realizar un análisis que no se ha hecho hasta ahora, ya que utiliza datos de censos y padrones de población que no fueron relevados por otros investigadores. Estas fuentes coloniales fueron y están siendo estudiadas por investigadores de otros países de América Latina, pero en el caso de Uruguay su utilización tiene un desarrollo más reciente con los estudios de la colonia de Sacramento, ${ }^{7}$ Canelones y Minas $^{8}$ y Santo Domingo de Soriano. ${ }^{9}$

\section{LA ECONOMÍA PREMODERNA EN URUGUAY}

El periodo que se analiza pretende abarcar los 100 años anteriores a la modernización de la economía. Al igual que con los antecedentes sobre

\footnotetext{
${ }^{5}$ Moraes, Pradera, 2008, p. 51.

${ }^{6}$ Ibid.

${ }^{7}$ Gelman, Campesinos, 1998.

${ }^{8}$ Moraes y Pollero, "Formas", 2003.

${ }^{9}$ Frega, Pueblos, 2007.
} 
estructura social, la historiografía que analizó la economía de este periodo se encargó de resaltar ciertos aspectos que se supone fueron los que determinaron el desempeño económico de la región, siempre adscrita al territorio del Uruguay actual.

Estos análisis se centraron en las cuestiones macro de la economía del periodo y se encargaron de resaltar los aspectos precapitalistas de esta, más que nada en las relaciones laborales, ${ }^{10}$ la escasez del desarrollo de manufacturas aparte del saladero y la debilidad de la agricultura, ${ }^{11}$ y el predominio del capital comercial, aun después de la independencia. ${ }^{12}$

Millot y Bertino consideran que los 100 años previos al auge agroexportador tuvieron un comportamiento homogéneo desde el punto de vista económico no cambiando sustancialmente su estructura. Según estos autores, se dan tres claros periodos de crecimiento, separados por ciclos de guerras importantes: 1778-1810 en el que la economía colonial se configura y expande; luego del ciclo revolucionario (1828-1842), en el que se produce una lenta recuperación hasta 1835 y luego un auge de la ganadería y el comercio, que arrastra a la agricultura, al saladero, a la construcción y a otras actividades, y 1852-1863, luego de la Guerra Grande, en el que también, después de una lenta recuperación, se da un fuerte crecimiento a partir de $1856 .{ }^{13}$ Hacia 1860 se configuran cambios que justifican hablar de otro periodo, tales como la consolidación de las estructuras de propiedad y tenencia de la tierra, la expansión del ganado ovino, el surgimiento de los bancos, el incremento de las relaciones de producción capitalistas y la relativa regularización de las finanzas estatales. ${ }^{14}$ Gran parte de los análisis se adentraron en la cuestión rural por ser en torno a esta donde se desarrolló la red de intercambio más importante de la región. Moraes destaca los tres aspectos que predominaron en esta visión en cuanto a la economía ruralpremoderna. El primero es el uso del suelo predominantemente ganadero que se caracteriza por el predominio de la explotación del ganado vacuno y el divorcio de la producción ganadera respecto de la agrícola. La explicación se basa en que la demanda externa privilegiaba el cuero vacuno y que el mercado interno era casi inexistente. Según esta visión esto llevó a un débil desarrollo de la economía agrícola que se remitió a las chacras de la jurisdicción de Montevideo y a la zona del litoral de la jurisdicción de Buenos Aires, donde la densidad de población era mayor. ${ }^{15}$

${ }^{10}$ Véanse Sala de Touron, Estructura, 1991, y Millot y Bertino, Historia, 1991.

${ }^{11}$ Millot y Bertino, Historia, 1991, y Barrán y Nahum, Historia, 1977, t. VI.

${ }^{12}$ Ibid.

${ }^{13} \mathrm{Ibid}$.

${ }^{14}$ Ibid.

${ }^{15}$ Moraes, Pradera, 2008, p. 18. 
El segundo aspecto que destaca la visión predominante es que el latifundio fue la unidad productiva básica del paisaje agrario. La abundancia de tierras y ganado en relación con los hombres, el "estilo tecnológico" de pastoreo natural que implicaba la ganadería (uso intensivo de la tierra y extensivo de la mano de obra), la indulgencia de las autoridades españolas en América, y el atraso de la legislación indiana y la voracidad de los agentes, son los aspectos que según la visión predominante dieron origen a una estructura de propiedad organizada en el latifundio. ${ }^{16}$ Como destacan los sugerentes aportes de Rosa Congost las leyes dictadas por los primeros gobiernos liberales en distintos países, a pesar de su lenguaje abstracto y aparentemente neutro, respondieron casi siempre a intereses de grupos particulares y se hallaron condicionados por la compleja realidad de los derechos de propiedad existentes en los países objeto de estudio. A su vez, los derechos, inclusive los de propiedad, son reflejo y producto de las relaciones sociales. ${ }^{17}$

Finalmente se hizo énfasis en un paisaje agrario volcado a abastecer mercados exteriores y carentes de mercados internos. El esquema propuesto es que este paisaje agrario ganadero-latifundista desarrolló una red de intercambios directos con las ciudades-puerto inhibiendo la formación de mercados internos. Como el cuero era el principal producto de exportación de la ganadería, se estableció un circuito de comercialización que lo conducía a las principales ciudades puerto donde era acopiado y exportado. Este circuito cerraba una red en la que los poseedores del capital mercantil eran también los dueños de los grandes latifundios, por lo que la producción y la exportación de cueros quedaba en las mismas manos inhibiendo eventuales derrames de valor por la creación de infraestructuras adyacentes de comercialización y financiación. ${ }^{18}$

En los últimos años se han cuestionado algunos de los rasgos que han caracterizado a estas visiones. Estudios de caso han demostrado la complementariedad de la producción ganadera con la producción agraria y han descubierto en la familia una unidad productiva básica del periodo (más que nada en la zona rural). ${ }^{19}$

Lo que se está intentando revisar es la insignificancia de la economía campesina en la historia rural, la relevancia de la complementariedad de la actividad agrícola y la imagen de una campaña despoblada y predominantemente habitada por un tipo de trabajador rural trashumante y temporal

\footnotetext{
${ }^{16}$ Gelman, Campesinos, 1998, y Moraes y Pollero, "Formas", 2003.

${ }^{17}$ Congost, Tierras, 2007, p. 13.

${ }^{18}$ Moraes, Pradera, 2008, p. 20.

${ }^{19}$ Gelman, Campesinos, 1998, y Moraes y Pollero, "Formas", 2003.
} 
(trabajadores imperfectamente asalariados como ser peones, jornaleros, puesteros y agregados) que pueden vincularse a la imagen del gaucho. ${ }^{20}$

\section{Métodos}

Se han utilizado padrones y censos de población de Montevideo y de las regiones aledañas relevados del periodo 1760-1860. A partir de estas fuentes se construyeron las categorías de análisis que recorrerán todo este trabajo, es decir, se crearon las variables que nos permitirán estudiar las características demográficas, sociales y productivas del sur del territorio de Uruguay. Se optó por utilizar padrones y censos de población por ser una fuente que brinda información sobre el tamaño de los hogares, la estructura de edades y sexo y la ocupación (principalmente la de los jefes de hogar).

El criterio de recopilación de datos se basó más que nada en la acumulación de estos sobre población en los periodos considerados (1760-1780; 1823-1826; 1836, y 1855-1858) y a partir de eso en la forma en que había sido levantado el padrón, es decir, en las variables que a partir de este se podían construir. En este sentido, si bien para cada año y cada región de estudio existen bastantes más recuentos de población que con los que se cuenta, sólo se levantaron y sistematizaron censos y padrones que tuvieran como mínimo el sexo de la persona, la edad, la posibilidad de identificar la unidad censal y la ocupación. Asimismo se intentó abarcar en cada periodo la mayor parte de poblados de la jurisdicción de Montevideo (como el caso de Maldonado que no forma parte de la jurisdicción de Montevideo, sino de la de Buenos Aires), si bien la idea no fue realizar un estudio con base en una jurisdicción, sino más bien teniendo en cuenta criterios territoriales y se mantuvo a Montevideo como un continuo en todos los periodos. Los datos de sexo y edad de las personas se trabajaron en forma de pirámides de edad. De estas a su vez se obtuvo el índice de masculinidad de la población y el índice de dependencia demográfica. Los datos de la unidad censal fueron trabajados como relaciones de parentesco respecto al jefe de hogar, así se realizó una taxonomía en donde el jefe de hogar es el que encabeza el mismo, seguido por la esposa, los hijos y así sucesivamente. A partir de esto se pudo identificar el peso de la familia nuclear en el hogar y la proporción de no parientes de cada uno de estos.

Los datos de la ocupación fueron analizados de dos formas: primero fueron clasificados según la rama de la economía a la que pertenecía la ocupación declarada -sector primario, secundario o terciario- con el ob-

${ }^{20}$ Moraes, Pradera, 2008. 
jetivo de aproximarnos a la estructura productiva y, segundo, fueron analizadas las ocupaciones rurales del declarante según fuese o no propietario de los medios de producción. El objetivo de esto era aproximarnos a la estructura social de la mano de obra rural.

De las fuentes que se utilizan, exceptuando el padrón que fue editado por Apolant, ${ }^{21}$ las demás fueron tomadas del Archivo General de la Nación de Montevideo (en adelante AGN) y del Archivo General de la Nación de Buenos Aires.

Se tiene en cuenta que estos padrones, como fuente estadística e histórica, cuentan con problemas de subregistro de la población y escasez de datos. Asimismo, dependiendo tanto del motivo por el que fueron levantados como del censista, muchas veces es difícil establecer un criterio de comparación entre ellos. Por este motivo se enfatiza aquí que este trabajo constituye una caracterización de ciertos aspectos del sur del territorio, lejos de pretender una cobertura total de la población ni una muestra estadística de los datos (véase cuadro 1).

\section{ASPECTOS SOCIODEMOGRÁFICOS DE LA REGIÓN}

Una de las primeras cuestiones que se plantearon al visualizar los datos demográficos del periodo es que esta sociedad está compuesta por familias, las cuales parecen ser las unidades productivas principales en las regiones rurales y un componente importante de las urbanas. Durante los años analizados se pudo comprobar que el patrón dominante que compone el hogar es una pareja con cuatro o seis hijos en promedio, si bien existen otros integrantes en el hogar como esclavos, dependientes, agregados o servicio doméstico, es menos significativos en su peso. En relación con los demás miembros del hogar, los hijos oscilan en promedio entre 35 y $60 \%$, si se toma en cuenta todos los años para los que contamos con registros. Respecto a las regiones, la nota distintiva es que en las urbanas (principalmente en Montevideo) los hogares están menos estructurados en torno a un núcleo familiar a diferencia de las rurales, más que nada porque la familia rural está abocada a la agricultura. Por consiguiente, se puede decir que mientras que las ciudades concentraban gran parte de los inmigrantes que se abocaban a desarrollar una actividad económica vinculada mayormente a actividades artesanales o al comercio, los alrededores de la ciudad concentraba a las familias campesinas que producían ya sea para el autoconsumo o para abastecer de productos a la capital (véase cuadro 2).

${ }^{21}$ Apolant, "Padrones", 1967. 


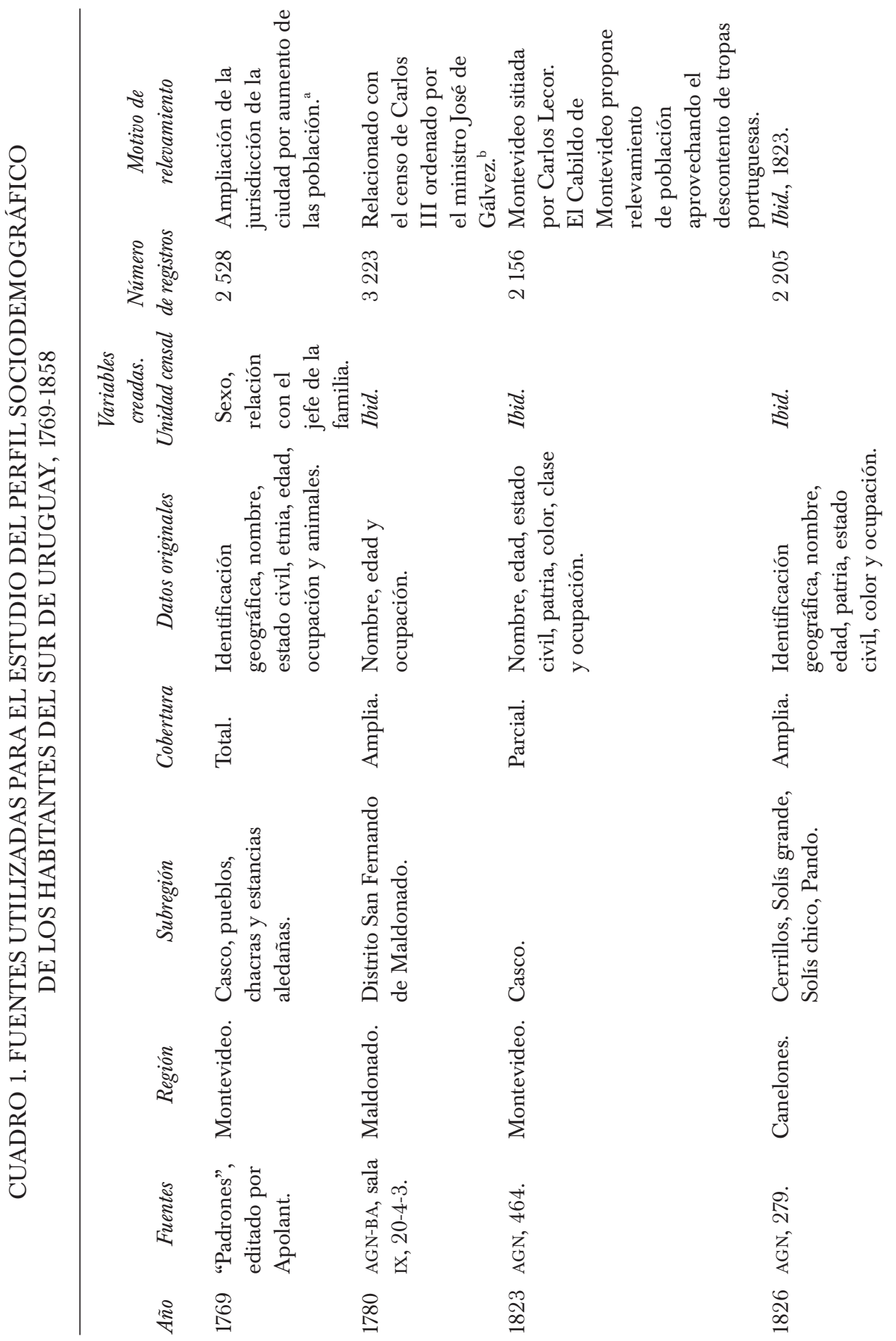




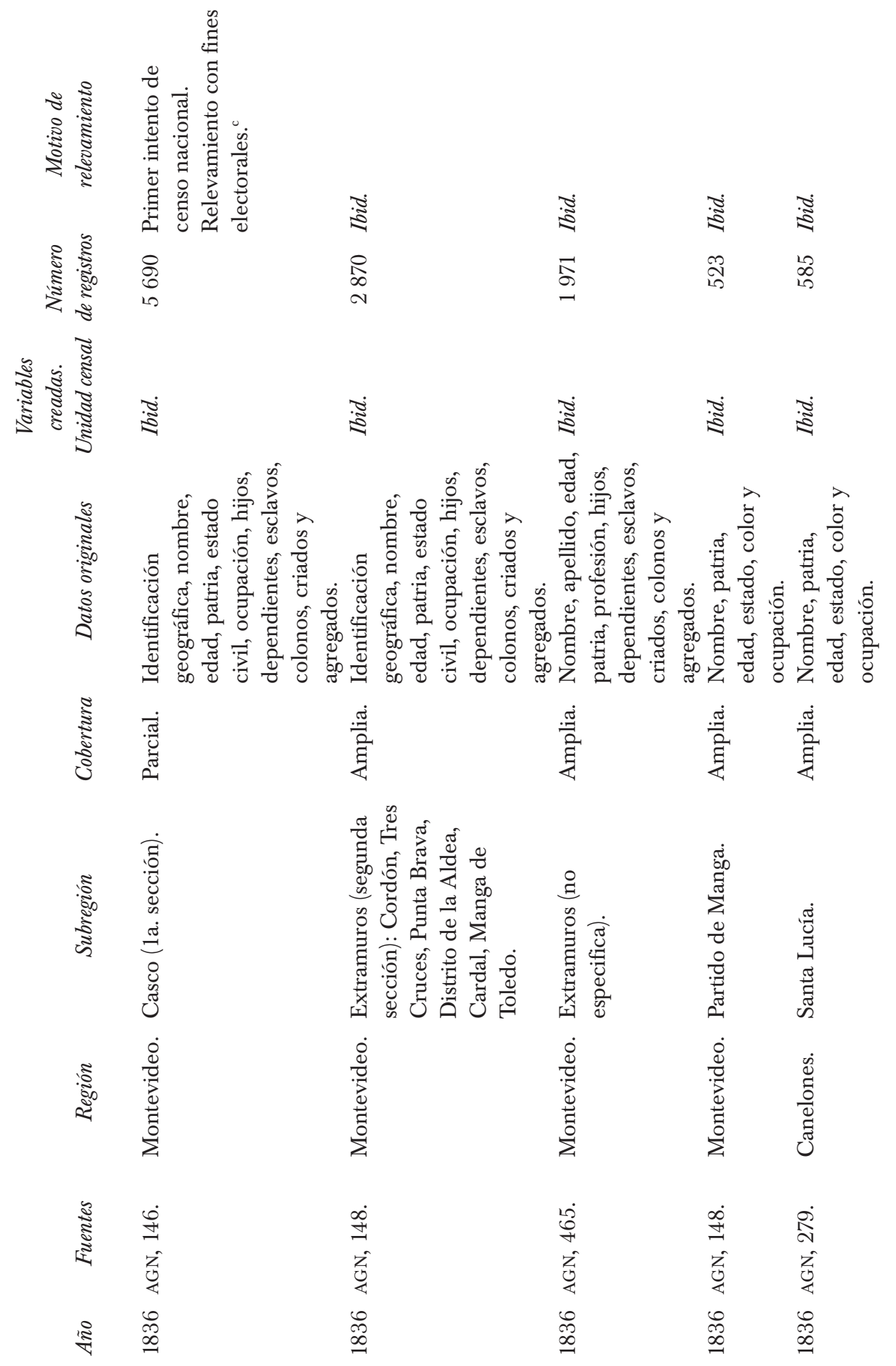




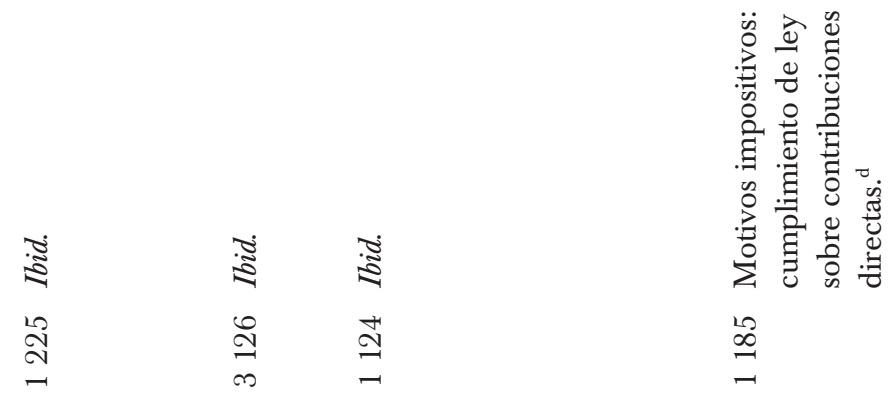

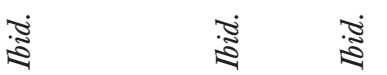

จุ๊
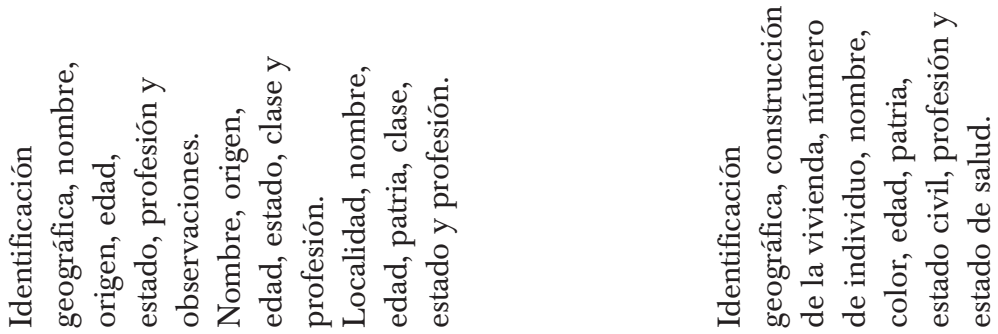

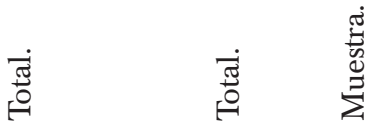

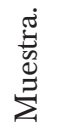

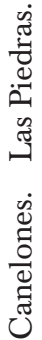

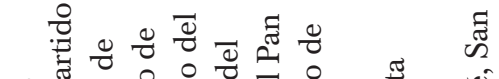

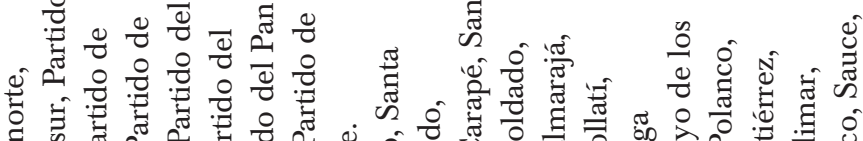

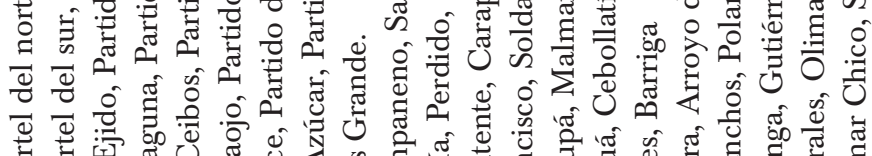

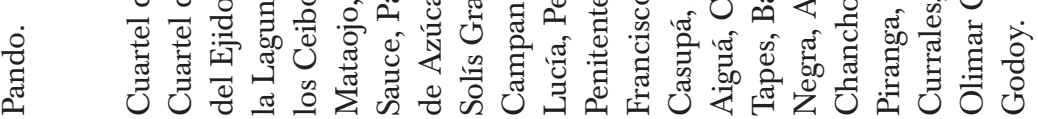

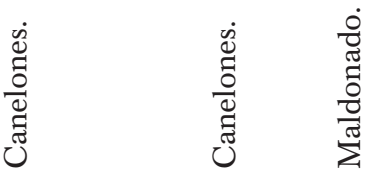

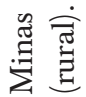

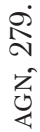

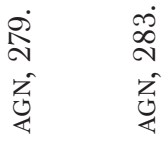

$\stackrel{\infty}{\infty}$

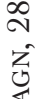

$\stackrel{\infty}{\infty}$

$\stackrel{\infty}{\infty} \underset{\infty}{\infty} \quad \stackrel{\infty}{=}$

10
10 


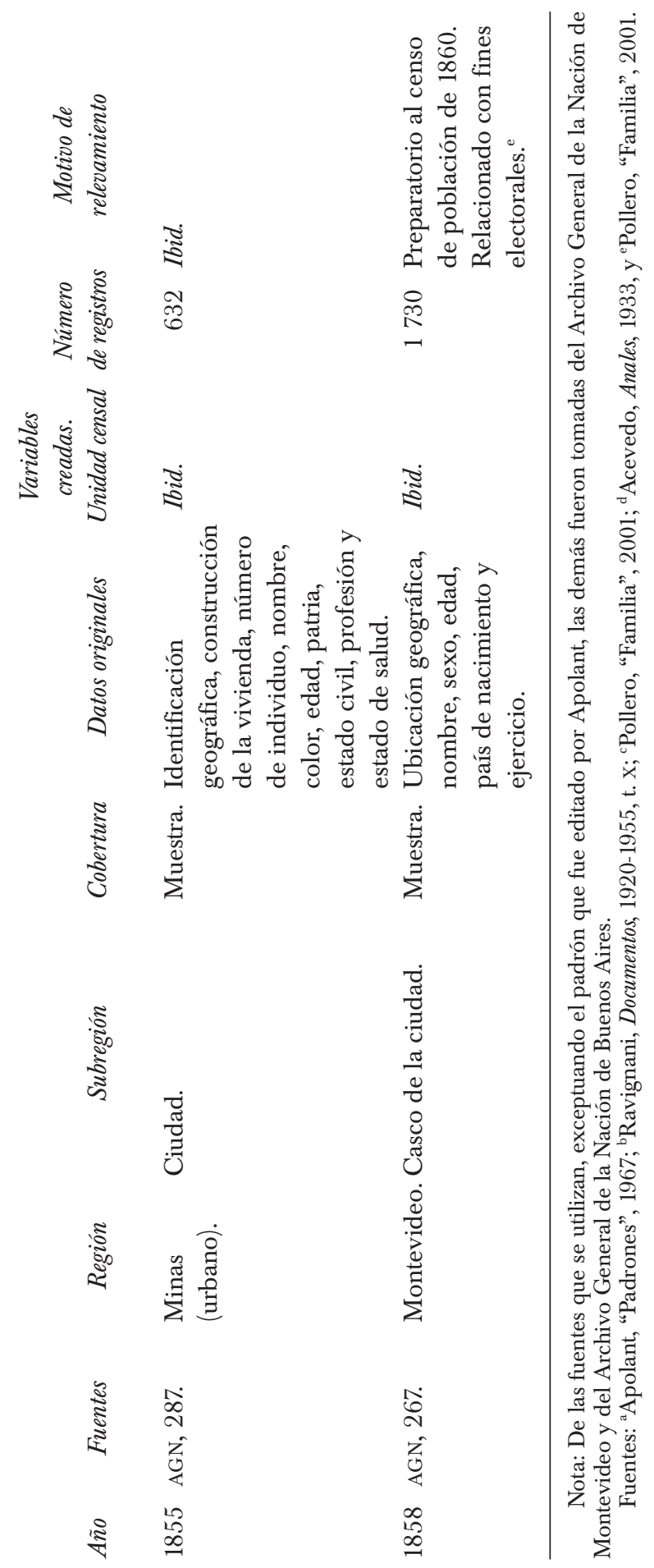




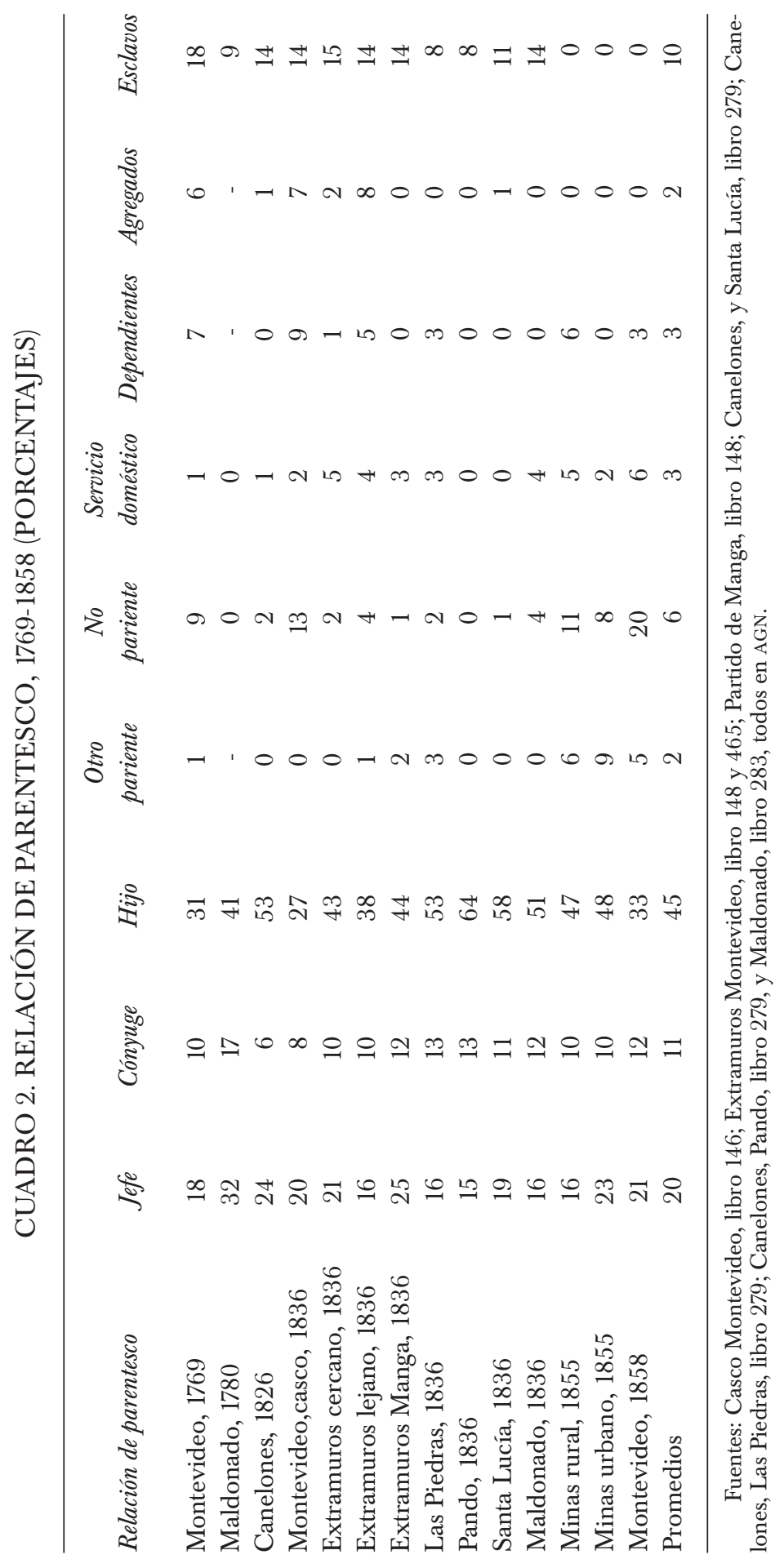


Asimismo, esta sociedad es en general joven en todas las regiones y se muestra masculinizada en las zonas rurales y más feminizada en las urbanas. Por ejemplo, en Montevideo y Minas rural, la relación de dependencia demográfica varía de 0.50 a 0.75 , siendo la más alta en el área rural.

Mediante la relación de parentesco en los hogares podemos aproximarnos a la composición de la mano de obra, ya que en gran parte de las regiones estamos analizando las chacras y estancias que es en donde las familias se vuelven unidades productivas. Como ya se dijo, es en las áreas rurales donde predomina el componente familiar de pareja e hijos. De este dato se puede extraer la conclusión de que gran parte de la mano de obra era familiar y, por consiguiente, libre. Si bien en Montevideo también existe un predominio de grupo familiar, se encuentran más casos de hogares compuestos por un jefe y los dependientes (de comercio, de pulpería, aprendices).

Los esclavos en los hogares constituyen $10 \%$ en promedio en todo el periodo, oscilando de 8 a 18\%. Los porcentajes mayores están siempre en Montevideo o en sus alrededores (fuera de los muros de la ciudad).

En síntesis, estamos ante la presencia de una sociedad relativamente joven en la que la familia es el componente principal. Si bien en la mayor parte de los años analizados es una sociedad esclavista, el porcentaje de esclavos declarados en los hogares hace pensar que estos no son el principal componente de la mano de obra.

\section{ESTRUCTURA OCUPACIONAL DEL SUR DE LA REGIÓN}

Para analizar la estructura ocupacional de cada padrón se utilizaron las ocupaciones declaradas por los censados. Este dato aporta conocimiento en cuanto a la estructura ocupacional, pero comparado con otro tipo de variables ocultan información y en general no presentan un contenido unívoco además de encubrir distintos sectores sociales dedicados a un tipo de actividad. ${ }^{22}$ Igualmente es un dato valioso que no aparece en todos los registros de la época. A continuación se realizará el análisis para los años seleccionados. Se le denominará periodo ya que dentro de los cortes de tiempo hay más de un año.

${ }^{22}$ Fradkin y Garavaglia, Busca, 2004. 


\section{Periodo 1769-1780. Montevideo-Maldonado}

Para este periodo contamos con 1292 registros de ocupaciones declaradas (22\% del total de los registros). En general, se trata de la ocupación del jefe de hogar y en algunos casos de alguno de los hijos mayores. De los dos padrones con los que se cuenta, el de 1769 tiene mala declaración de la ocupación. En este están sobrerrepresentadas las ocupaciones como peón o dependiente y es poco específico en cuanto a la actividad del jefe (en gran parte de los casos no se registra la ocupación del jefe y sí la de los peones miembros del hogar). Del total de la población, 13\% de la mano de obra es esclava. Como se mencionó anteriormente, es difícil realizar un supuesto de la cantidad de población activa de este periodo por la omisión en la declaración de la edad o la mala declaración de esta. Igualmente, podemos aproximarnos a una cifra de $37.4 \%$ de población activa. ${ }^{23}$

La ocupación predominante en estos padrones es la de labrador. El labrador es un agricultor, campesino, dedicado al cultivo para el autoconsumo o para abastecer mercados locales pequeños. En ciertos casos pueden combinar los cultivos con la cría de animales. La presencia mayoritaria de labradores da cuenta del carácter agricultor de la zona. Esto se explica en parte por el territorio que estamos considerando: las chacras aledañas a Montevideo.

De los que registran esta actividad, 91\% está censado como jefe de hogar, seguido de $6.3 \%$ de dependientes. Figuran algunos hijos o esclavos, pero como casos aislados. Asimismo, 88\% de estos jefes son hombres.

En el sector ganadero muchos de los censados están registrados como peones de estancia. Ya que también corresponden a estancias aledañas a Montevideo y Canelones, podemos suponer que en muchos de los casos el propietario de la estancia residía en el casco de Montevideo. ${ }^{24}$

Respecto al sector secundario, la mayoría de los registrados figura con actividades asociadas al cuero, principalmente zapateros. Dentro de los otros rubros están los plateros, carpinteros, torneros, etc., y en este conjunto, la mayor parte son jefes de hogar hombres (maestro carpintero, maestro zapatero y sus dependientes).

Finalmente, el sector terciario corresponde a $27 \%$ de la actividad económica, de donde destaca principalmente el comercio con $62 \%$ del sector.

\footnotetext{
${ }^{23}$ Se toma en cuenta a la población mayor de quince años y menor a 65 y a todos los esclavos. Si bien se reconoce la existencia de trabajo en los menores de edad, se usa el anterior criterio a efecto de hacer más fácil la comparación.

${ }^{24}$ En el padrón editado por Apolant se hace referencia a esto cuando se anota a las personas que viven en un hogar rural aclarando que el dueño de la estancia vive en la casa en Montevideo (se hace referencia a la unidad censal).
} 


\section{Periodo 1823-1826. Montevideo y Canelones}

Para este periodo contamos con un total de 1983 ocupaciones registradas de un total de 2850 personas en edad activa (70\% de la población potencialmente activa tiene ocupación registrada). Los esclavos representan $11 \%$ de la población activa y $7 \%$ de la población total. Como no se cuenta con la ocupación de los esclavos, estos no fueron incluidos en los sectores, pero se asume que en gran parte de los casos estaban vinculados a la actividad económica del jefe de hogar.

Por contar con el casco de Montevideo en este periodo los datos muestran una predominancia del sector terciario y dentro de este el comercio. En cuanto al sector primario, al igual que en el periodo anterior, $91 \%$ de los registrados se encuentra relacionado a actividades agrícolas. El resto son ocupaciones aisladas vinculadas al sector.

El 96\% de los registrados en estas ocupaciones están como jefes de hogar, solamente $2 \%$ como hijos y el resto son dependientes. A su vez, $99 \%$ son hombres. Respecto al sector vinculado a la ganadería, la mayor parte de los registrados con ocupación se distribuye entre estanciero y hacendado. ${ }^{25}$ Sólo un porcentaje muy bajo $(8 \%)$ figura como ganadero y como capataz de estancia.

En el sector secundario se destacan actividades vinculadas a lo textil y al cuero; estas más que nada están relacionadas con la vestimenta y son típicamente urbanas. Respecto al sector textil, la mayor parte son costureras y sastres, $64 \%$ está compuesto por mujeres y 35\% restante por hombres. Estas mujeres corresponden al padrón de Montevideo de 1823 que como mencionamos anteriormente tiene la peculiaridad de ser un registro de población activa que cuenta con la ocupación de las mujeres; estas son en su mayoría jefas de hogar y las ocupaciones que más se registran son las de costurera y lavandera.

Finalmente, el sector terciario es el mayoritario de los tres que analizamos. La actividad privilegiada es la del comercio con 63\%. La mayor parte de los registrados en esta categoría declara "comercio" o "comerciante". En general, no hay una especificación de la tarea que realizan, por lo que no se puede saber si forman parte del alto comercio o si son dependientes de una tienda. En algunos casos se especifica la tarea, pero en pocas ocasiones. La actividad del comercio es seguida por la de pulpero con $27 \%{ }^{26}$ Los demás casos registrados son poco significativos en el sector.

\footnotetext{
${ }^{25}$ Tanto al estanciero como al hacendado se los vincula a la producción de ganado extensiva. Implica la cría de animales en grandes proporciones de tierra.

${ }^{26} \mathrm{El}$ pulpero es propietario de una tienda pequeña que vende productos variados para abastecer a la villa cercana. Proveía todo lo indispensable para la vida cotidiana: comida, bebida,
} 
De los registrados en este sector, $84 \%$ figura como jefes de hogar, seguido de $6 \%$ de dependientes. Finalmente, $98 \%$ son hombres y el $2 \%$ restante son mujeres. En el sector terciario el comercio representa 61\%; lo siguen los servicios donde se encuentran ocupaciones como barbero, imprentista, peluquero y lavandera, entre otras. Después de estas, las actividades más importantes están vinculadas a la administración pública, la milicia y el servicio doméstico.

Resulta difícil interpretar que en este periodo la economía se vuelque hacia el sector terciario, igualmente se puede decir que hay una tendencia al crecimiento de las actividades ligadas al comercio en el conjunto de la región. Si bien es innegable que la economía se está diversificando y que probablemente el sector terciario cobre importancia, se debe relativizar la imagen de una economía abocada a este sector. En este caso se tomará solamente como una tendencia y no como valores que den cuenta de un dato contundente.

\section{Periodo 1836. Montevideo, Canelones y Maldonado}

De 17114 registrados en 1836 contamos con 3771 ocupaciones, y se calcula que $49 \%$ es población potencialmente activa, por lo que se contaría con $45 \%$ de las ocupaciones de los registrados potencialmente activos. De esta población $26 \%$ está formada por mano de obra esclava. ${ }^{27} \mathrm{Al}$ igual que en el periodo anterior, la mayor proporción de las ocupaciones declaradas se encuentra en el sector terciario. En cuanto al sector primario, como se vio en los periodos anteriores, existe una fuerte predominancia de la agricultura sobre la ganadería con 56 y $21 \%$, respectivamente. La amplia mayoría de los trabajadores vinculados al sector agrícola se declara labrador; igualmente, hay un pequeño matiz de otras actividades, pero es poco significativo para el sector en su conjunto. De los registrados en este sector, $23 \%$ es jefe de hogar; $51 \%$ hijo; $11 \%$ esposa, y $8 \%$ esclavo. El resto se divide en dependientes, no parientes y otros parientes vinculados al jefe. La gran proporción de hijos da la idea de que en esta actividad se utilizaba ampliamente la mano de obra familiar.

En el sector ganadero, la gran mayoría de los registrados figura como hacendado. Hay otras actividades declaradas, pero son aisladas dentro del conjunto. De las personas registradas en este sector 16.8\% figura como jefes de hogar, $57.9 \%$ como hijos y $10.6 \%$ como esclavos. Los demás se

\footnotetext{
velas, carbón, remedios, telas, etc. También era un lugar de reunión social. Son característicos de las zonas rurales del río de la Plata.

${ }^{27}$ Se cuenta aquí el total de los esclavos y no sólo los activos.
} 
distribuyen entre otros miembros del hogar como otros parientes y dependientes. $\mathrm{Al}$ igual que en la actividad agrícola, la alta presencia de hijos da la idea de una actividad que utilizaba mano de obra familiar; si bien se puede suponer que de forma menos intensiva que la agrícola.

Respecto al sector secundario las actividades más desarrolladas son la madera $(24 \%)$ y el metal $(23 \%)$, seguido del cuero $(21 \%)$ y la textil $(18 \%)$. De los trabajadores vinculados con la madera, la gran mayoría de estos son carpinteros; los vinculados al cuero son sobre todo zapateros y talabarteros; los vinculados al metal son plateros, y finalmente los vinculados a los textiles son principalmente sastres. Aparecen otras ocupaciones como talabarteras o costureras, pero en este caso son aisladas.

En relación con el sector terciario, al igual que en los otros periodos, el comercio figura como la actividad principal con 56\% del sector. De los registrados en esta actividad 51\% figura como comercio y $33 \%$ como comerciante o dependiente de comercio. Aparecen algunos pulperos, taberneros ${ }^{28}$ y repartidores, pero como actividades aisladas. En el sector del comercio en su conjunto, $49 \%$ de las personas están registradas como jefe de hogar y 33\% como dependientes de comercio. El resto se divide entre otros integrantes del hogar con $11 \%$ de no parientes y $5 \%$ de hijos. Asimismo aparecen otras actividades vinculadas a la enseñanza (maestros de escuela), religiosos y personas vinculadas a la administración y al puerto. Todas estas resultan mínimas comparadas a la magnitud del comercio.

De forma similar al periodo anterior, este muestra una tendencia al crecimiento de las actividades ligadas al sector terciario y principalmente al comercio. Al igual que en el periodo 1823-1826 esto se interpreta solamente como una tendencia.

\section{Periodo 1855-1858. Montevideo y Minas}

Para el periodo 1855-1858 contamos con 5387 ocupaciones registradas de un total de $15709,{ }^{29}$ lo que constituye $34 \%$ del total y $51 \%$ de los potenciales activos. En este periodo contamos con toda la mano de obra libre. A diferencia de los demás, estos padrones muestran equiparadas las actividades agrícolas y ganaderas dentro del sector primario, con una leve preponderancia de la ganadera. En la actividad agrícola, 93\% figura como labradores y el porcentaje restante como quinteros. ${ }^{30}$ En cuanto a la acti-

\footnotetext{
${ }^{28}$ Tabernero es el dueño o trabajador de una taberna.

${ }^{29}$ Con la muestra ponderada.

${ }^{30}$ Propietarios o trabajadores de quintas donde se realizan plantaciones en pequeña escala con la posible combinación con cría de animales.
} 
vidad ganadera, todos los registrados aparecen como estancieros. Otras ocupaciones que aparecen en los padrones son peones o peones jornaleros con $62 \%$, guadañeros $14 \%$, y pescadores $8 \%$. De los registrados en el sector agrícola $80 \%$ son jefes y el $20 \%$ restante están registrados como hijos. La actividad ganadera muestra un comportamiento diferente ya que 77\% figura como jefe de hogar y el porcentaje restante se distribuye entre otros parientes y no parientes. Si bien no se puede pensar que una actividad hacía excluyente a la otra, más bien pensamos en una combinación de ambas; las relaciones de parentesco muestran que la actividad agrícola es más propensa a utilizar la mano de obra familiar que la ganadera.

Respecto a la actividad secundaria se destacan los oficios vinculados al cuero, textil y madera. De los registrados con actividades relacionadas al cuero, $96 \%$ son zapateros y el resto se compone de talabarteros. Las actividades textiles muestran una diversificación levemente mayor, aunque las actividades se concentran principalmente en los sastres seguido de costureras. Finalmente, entre los oficios vinculados a la madera los carpinteros son los que tienen el mayor porcentaje (85\%); los demás se distribuyen entre aprendices de carpintero y trabajadores en barracas de madera.

El sector terciario es el que predomina en la economía de este periodo. $\mathrm{Al}$ igual que en los otros el comercio sigue siendo el sector que concentra mayor cantidad de trabajadores. El sector de servicios crece en este periodo y muestra una diversificación mayor que la de los anteriores. Se trata en su mayoría de actividades propias del ámbito urbano y dan cuenta de una población en crecimiento. Como se puede observar, el sector en su conjunto muestra una diversificación considerable, de donde resaltan los cocineros y las planchadoras con 23 y $21 \%$, respectivamente.

El conjunto del periodo muestra un peso importante de las actividades ligadas al sector terciario y principalmente al comercio y los servicios. Asimismo, se puede visualizar una tendencia a la diversificación de las ocupaciones, lo que resulta coherente por el periodo que estamos analizando. Al igual que en los casos anteriores el peso del sector terciario se ve como una tendencia que está fuertemente relacionada con la actividad en la ciudad de Montevideo. Igualmente, el dato es relevante ya que Montevideo es la región más densamente poblaba de las analizadas y gran parte de las actividades del sur giran en torno a la ciudad puerto, a pesar de que en este periodo se supone que las regiones aledañas han adquirido una autonomía importante. 


\section{MONTEVIDEO DENTRO DE LOS PAISAJES DEL SUR}

\section{Evolución de los sectores de la economía}

a) El sector primario ha sido de los más analizados por la historiografía del periodo. Como se mencionó en los antecedentes, la historiografía tradicional construyó la imagen de una sociedad segmentada en la que se privilegió la ganadería como principal recurso -refiriéndose más que nada a las regiones rurales. La historiografía más reciente analiza la complementariedad del sector y relativiza la imagen de una campaña vacía destacando la unidad familiar como principal productora de recursos. ${ }^{31}$ Esta apreciación se enfatiza en el caso del sur del territorio, donde encontramos en todo el periodo una alta proporción de la población ocupada en actividades agrícolas.

En todos los padrones de Montevideo analizados, a excepción del primero, la actividad primaria es la de menor importancia, la terciaria es la más significativa y la secundaria se ubica en el segundo lugar. La calidad de los datos no permite sacar conclusiones contundentes acerca de la evolución de la estructura ocupacional en Montevideo, lo cual se debe a que en el correr del periodo considerado este fue expandiéndose y muchas veces los datos están sesgados por la propia expansión. Por este motivo, resulta complejo comparar la variación de estos a lo largo del periodo, sin embargo, se puede visualizar de forma aproximada cómo se comporta cada sector, así como las actividades que se privilegian en cada uno de estos.

A excepción de 1769, en todos los demás padrones la actividad principal declarada dentro de la actividad primaria es la pesca, que en el caso de esta taxonomía se encuentra dentro de "otros" del sector primario. Esto es de esperarse por tratarse de una ciudad portuaria. Si pensamos en Montevideo como una ciudad que gira en torno a su puerto y en expansión, es razonable que la pesca sea una de las actividades primarias privilegiadas. Asimismo, mediante la expansión de la ciudad, las zonas que en un primer momento eran chacras de Montevideo pasaron a formar parte de la ciudad, o bien a ganar autonomía y transformarse en regiones agrícolas "independientes" de Montevideo. A continuación, la gráfica 1 muestra la evolución del sector primario entre 1769 y 1858 en Montevideo.

b) La historiografía que ha estudiado el periodo del sector secundario ha destacado el bajo desarrollo de este o bien su carácter artesanal. El argumento básico es que los requerimientos de las clases superiores se cubrían con las importaciones españolas y extranjeras, y los del resto de la pobla-

${ }^{31}$ Gelman, Campesinos, 1998; Garavaglia, Pastores, 1999, y Moraes, Pradera, 2008. 


\section{GRÁFICA 1. EVOLUCIÓN DEL SECTOR PRIMARIO \\ EN MONTEVIDEO, 1769-1858}

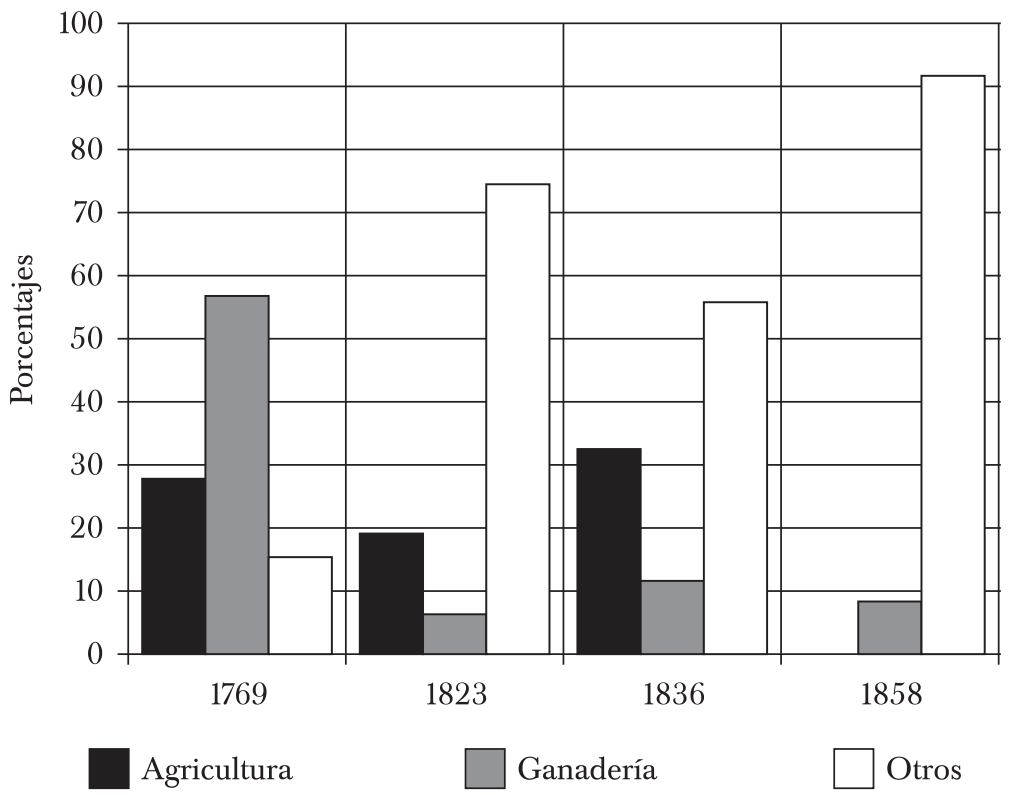

Fuentes: Padrón de Montevideo de 1769; Apolant, "Padrones", 1967; para 1823, AGN, libro 464, censo de Montevideo; para 1836, AGN, libros 146 y 148, Extramuros de Montevideo, y libro 465, Padrón de Montevideo, y para 1858, AGN, libro 267.

ción con los limitados efectos que producía el resto del virreinato o lo que llegaba a través del contrabando portugués. La producción era mínima por lo reducido del mercado y la competencia de las importaciones. La artesanía fue escasa y limitada a oficios imprescindibles y simples y no existió un régimen cooperativo de los oficios con carácter limitativo y un control de la producción. Se destacan oficios en los que se utilizó el aprendizaje. ${ }^{32}$

Las ocupaciones dentro de este sector se distribuyen de forma más o menos uniforme, a excepción de Montevideo que en 1769 registra más que nada a personas vinculadas al cuero, principalmente zapateros. En todo el periodo cobran importancia las actividades vinculadas al cuero (zapateros), textil (principalmente sastres), madera (más que nada carpinteros) y metal (herreros, plateros). Generalmente aparecen en los padrones los jefes de hogar con una ocupación y un dependiente relacionado con esa ocupación. Esto da la idea de talleres artesanales en donde se llevaba a

${ }^{32}$ Sala de Touron y Alonso, Estructura, 1991, y Millot y Bertino, Historia, 1991. 
cabo la actividad como oficio. A diferencia de los padrones de las zonas rurales, en Montevideo estas actividades cobran especial importancia en todos los periodos considerados. Con excepción del primer periodo, en todos los años considerados, la actividad secundaria representa más de 16\% del total. En la gráfica 2 se observa la tendencia a la diversificación del sector secundario. Hay que tomar en cuenta que en todos los padrones esta es la actividad de menor importancia.

c) El sector terciario también ha sido estudiado ampliamente con especial énfasis en Montevideo. Dentro de este destaca el comercio de exportación por la importancia del puerto y el comercio minorista que proveía productos básicos a una población en aumento. Como ya se mencionó, el comercio a partir de 1778, y sobre todo a partir de 1783, después de la paz con Inglaterra, aumentó su tráfico por Montevideo debido a las condiciones de su puerto y a los privilegios concedidos por la corona. Montevideo se beneficia en especial del tráfico negrero, del comercio de intermediación con Buenos Aires y con el Pacífico, de la venta de tasajo a Cuba, de las disposiciones que autorizan importar y exportar desde y hacia las colonias extranjeras y, durante las guerras con Inglaterra, de las negociaciones con neutrales. La historiografía destaca el rápido crecimiento del comercio en Montevideo y junto a este el surgimiento de una capa de monopolistas. Se resalta asimismo la primacía del capital comercial frente al productivo y la imposibilidad de formar un mercado único. ${ }^{33}$ También, en este sector destacan las tareas que giraban en torno al puerto de Montevideo. Según Arturo Betancur, el puerto colonial de Montevideo alcanzó en los últimos 40 años de dominio español un creciente protagonismo, basado fundamentalmente en su situación geográfica. En sucesivas etapas se convirtió en terminal de buques correos, apostadero naval del Atlántico Sur, sede de oficinas administrativas específicas, destino de buques mercantes, corsarios y negreros, nudo de comunicaciones regionales, etc. En torno a este crecía una población muy dinámica ya que recibía inmigrantes transatlánticos y de la región. A su vez, progresaba en él una plaza comercial incentivada por diferentes oportunidades, la mayor parte de las cuales coincidieron con la guerra hispano-británica iniciada en 1797. En el puerto de Montevideo se intermediaban muchas cosas: se salaban toneladas de carne y bullía el espíritu mercantil estimulado por una apertura inestable. ${ }^{34}$

Según los datos, en Montevideo el sector terciario es el mayor en importancia (excepto 1769). En el transcurso del periodo, excluyendo el primer año considerado, la actividad terciaria oscila entre 65 y $80 \%$ del total de las actividades declaradas y se ubica siempre en el primer lugar. Esto

\footnotetext{
${ }^{33}$ Millot y Bertino, Historia, 1991.

${ }^{34}$ Betancur, "Provisión”, 1996, p. 123.
} 


\section{GRÁFICA 2. EVOLUCIÓN DEL SECTOR SECUNDARIO} EN MONTEVIDEO, 1769-1858

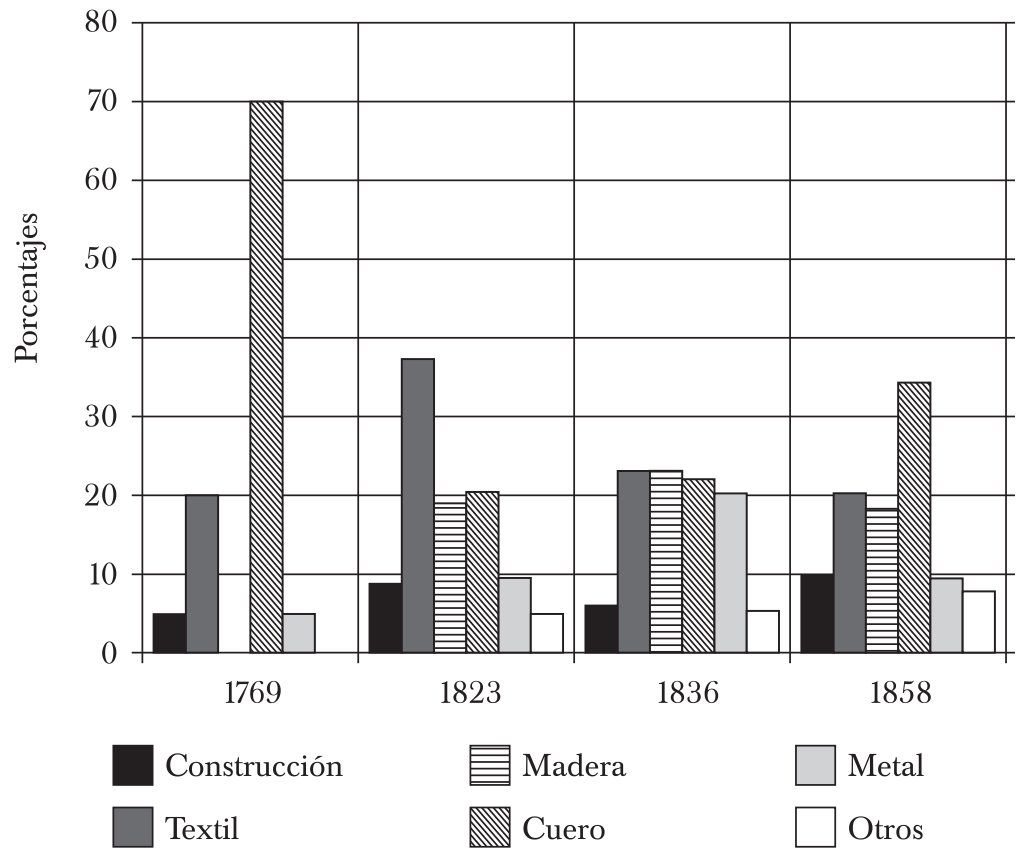

Fuentes: Padrón de Montevideo de 1769; Apolant, "Padrones", 1967; para 1823, AGN, libro 464, Censo de Montevideo; para 1836, AGN, libro 146 y 148, Extramuros de Montevideo, y libro 465, Padrón de Montevideo, y para 1858, AGN, libro 267.

se explica porque estamos hablando del casco urbano donde cobran importancia las actividades comerciales y las ligadas a la vida de la ciudad. Dentro del sector el comercio cuenta con una abrumadora mayoría y los servicios se ven incrementados hacia el final del periodo (véase gráfica 3).

En los años seleccionados la evolución de los sectores se comporta de forma similar, exceptuando 1769 cuyo padrón es privilegiadamente rural. Como se mencionó, los datos muestran de forma aproximada cómo se comporta cada sector en el casco de la ciudad. Se puede decir que a partir de 1823 los padrones de población de Montevideo muestran una estructura ocupacional dirigida hacia el sector terciario, en donde el comercio se muestra como actividad principal. Esta estructura ocupacional es diversificada, aunque hay actividades que se repiten con mayor frecuencia, como el comercio o ciertos oficios artesanales. El crecimiento del sector servicios y 
GRÁFICA 3. EVOLUCIÓN DEL SECTOR TERCIARIO

EN MONTEVIDEO, 1769-1858

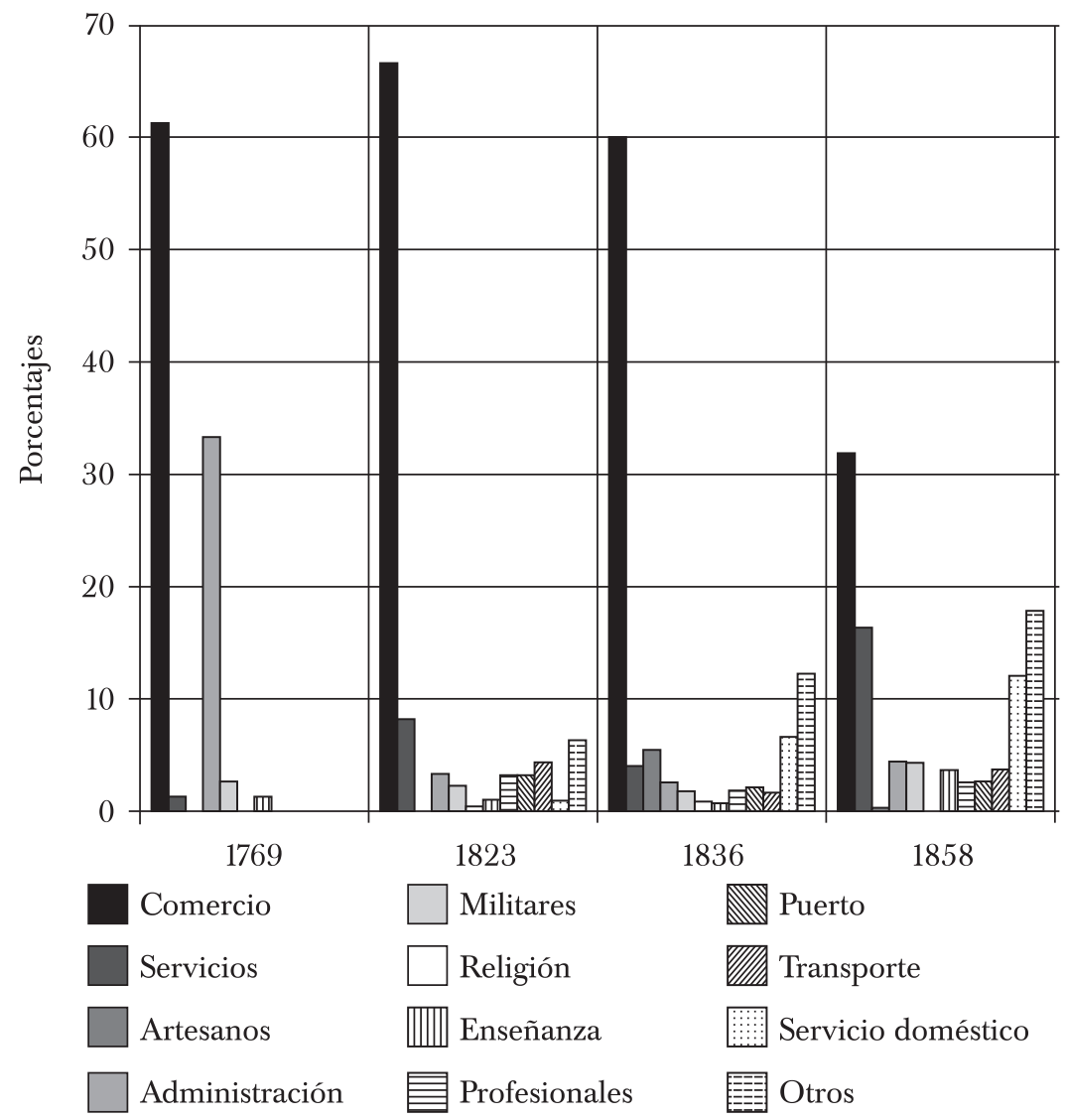

Fuentes: Padrón de Montevideo, de 1769; Apolant, "Padrones", 1967; Montevideo, 1823, AGN, libro 464, censo de Montevideo; para 1836, AGN, libro 146 y 148, Extramuros de Montevideo, y libro 465, Padrón de Montevideo, y para 1858, AGn, libro 267.

la diversificación ocupacional hacia el final del periodo da la idea de una expansión de la población.

Si bien la calidad de los datos no permite hacer afirmaciones contundentes acerca del peso de los sectores en el conjunto de la economía, la evolución y la forma que toman estos datos parecen ser lo suficientemente acertadas como para afirmar lo dicho anteriormente. En una economía en expansión, con una población creciente, es probable que las actividades comerciales se hayan incrementado y que el sector servicios cobre importancia. 


\section{CONCLUSiOnes}

\section{El sur de Uruguay en el contexto regional.}

Una aproximación a la geografía económica

Para los efectos de describir una geografía económica en este artículo se partió de la hipótesis de que existen dos paisajes agrarios en el comienzo del poblamiento de Uruguay: el sudatlántico y el antiguo norte misionero. Esta hipótesis cuestionó el análisis histórico del territorio como un todo homogéneo desde el punto de vista tanto económico como social. En este caso se analizaron características sociodemográficas, productivas y de la estructura social del paisaje sur del territorio. Dentro del sur de Uruguay se consideraron regiones diversas, en primer lugar por la característica de los datos, es decir, en general no se cuenta con datos continuos de todas las localidades analizadas; en segundo lugar, fue relevante conocer la diversidad del paisaje dentro del propio sur del territorio para poder visualizar los vínculos que existían entre estos así como el perfil sociodemográfico de cada una de las localidades.

Como todos los territorios, el sur de Uruguay cuenta también con matices específicos que son asimilables a otras regiones del territorio. De los padrones analizados se pueden diferenciar tres regiones: en primer lugar Montevideo, la ciudad portuaria con una estructura ocupacional orientada a las actividades comerciales y una diversificación ocupacional importante. En esta región los padrones de población (exceptuando el de Montevideo en 1769) muestran una actividad primaria escasa, y cuando esta se presenta es principalmente con actividades relacionadas al puerto como la pesca.

En Montevideo se constata una presencia mayor de hogares no estructurados en un núcleo familiar que en las áreas rurales, si bien la familia es el elemento común en el continuo del territorio y periodo analizado. Además, la presencia de no parientes en el hogar es un elemento importante en el casco de la ciudad. Estas personas generalmente están vinculadas a la actividad del jefe en calidad de dependientes o aprendices, dependiendo de la tarea que este realice. Se puede decir que en la ciudad hay una mayor proporción de personas residiendo en conjunto en torno a una actividad económica. Esto es típico en ciertos oficios que cuentan con aprendices o de negocios que utilizan dependientes.

Montevideo cuenta también con una población relativamente masculinizada en el conjunto del periodo que se equilibra al final de este. Esto se asocia a la atracción de inmigración, mayoritariamente de sexo masculino. Como ha sido descrito por la historiografía, Montevideo a lo largo del periodo parece haber sido foco de atracción de inmigración (principalmente 
masculina) que llegaba en busca de las oportunidades que brindaba el comercio en expansión. El registro de hogares en el que conviven hombres en torno a una actividad común, ya sea comercial o vinculada a un oficio, refuerza esta idea.

De todas las localidades analizadas esta es la más densamente poblada y en la que se centralizan las actividades administrativas y de servicios que en las otras localidades no aparecen. La diversificación cada vez mayor y el crecimiento de los servicios hacia el final del periodo dan la idea de una población y una economía en expansión.

Por ser una ciudad puerto que concentra gran parte de la actividad económica de la región, el desarrollo de Montevideo, aunque posterior, resulta bastante similar al de Buenos Aires. Ambas ciudades puerto del río de la Plata fueron dinámicas en el comercio de ultramar. Según González Lebrero la dinámica de crecimiento demográfico en Buenos Aires estuvo fuertemente condicionada por el arribo permanente de personas de diversa condición, atraídas por el movimiento comercial y el complejo entramado de demandas que este suponía. Destacándose con nítidos perfiles la actividad comercial y dentro de esta los intensos intercambios con Brasil y Angola, se encontraban en los miembros de casi todos los sectores sociales un grupo importante de portugueses. La dinámica desarrollada por el puerto fue un señuelo que capturó a otros personajes de diversas ciudades del virreinato peruano que se acercaban por los efectos del dinamismo. Muchos de estos se avecinarían definitivamente en esta ciudad. ${ }^{35}$

En segundo lugar, los padrones analizados muestran localidades volcadas casi enteramente a actividades relacionadas a la agricultura. Estos son los casos de las chacras y extramuros de Montevideo, Canelones y Maldonado. La proximidad de esta región con Montevideo fue crucial para el comienzo del desarrollo de las actividades agrícolas. Durante los periodos de paz esta región se favorecía del acceso al mercado montevideano y durante la guerra -que fue la situación casi continua a lo largo del siglo XIX- los ataques a Montevideo provocaban despoblación y abandono de las tareas productivas. ${ }^{36}$ Asimismo, gran parte de las tierras de esta región habían sido concedidas a los pobladores de Montevideo, principalmente las chacras aledañas a la ciudad y la zona de Canelones. El caso de Las Piedras -por ejemplo- es el de una población tradicionalmente cerealera y con predominio de la pequeña propiedad, mientras que Pando fue una zona de estancias concedidas a los pobladores de Montevideo. ${ }^{37}$ Las regiones aledañas a Montevideo fueron también concedidas a los habitantes

\footnotetext{
${ }^{35}$ González, Pequeña, 2002, p. 87.

${ }^{36}$ Moraes y Pollero, "Categorías", 2010, p. 9.

${ }^{37}$ Ibid., p. 19.
} 
iniciales y también se trata de pequeñas propiedades. Si bien la región en su conjunto nació principalmente para proveer a la ciudad de alimentos, y probablemente haya hecho sustentable en el tiempo a un amplio conjunto de productores trigueros, se puede constatar mediante otros estudios realizados que a partir de su función económica original esta lentamente fue ganando autonomía propia.

El paisaje que se está describiendo es diferente al de la ciudad; en primer lugar por las actividades que en este se realizan, pues se trata de una región abocada enteramente a la actividad primaria y dentro de esta a lo agrícola. Esta región cuenta durante todo el periodo analizado con una relativamente escasa diversificación de ocupaciones. En todas estas localidades, la actividad ganadera es muy poco significativa y casi no se registran actividades ligadas a lo urbano como podrían ser la administración o los servicios (exceptuando el caso de Maldonado que constituye una villa y fuerte militar).

En segundo lugar, la característica de estas regiones es que la unidad productiva básica está basada en la familia. Si bien las unidades censales incorporan a personas que no pertenecen al núcleo familiar -sobre todo esclavos hasta el año 1836-, se pude decir que la mano de obra principal que se utiliza es la familiar. Esto se constata por la alta presencia de hijos en los hogares que en muchos casos declaran la misma actividad del jefe cuando están en edad activa. Esta evidencia es consistente con lo que han señalado estudios previos sobre las características económicas de esta zona sureña, cuya economía rural siempre se ha dicho que es más diversificada que la de las zonas del norte y noreste. Puede decirse entonces que, al menos en las áreas cubiertas por este estudio, la generalización de una sociedad rural desarticulada, con poco peso de las familias y contingentes de "hombres sueltos" errantes por la campaña, queda cuestionada.

En tercer lugar, estas poblaciones son menos masculinizadas que Montevideo, exceptuando ciertos casos de los extramuros. La explicación de esto es que aquí encontramos un porcentaje mayor de familias en donde en la mayoría de los casos está registrada la esposa luego del jefe de hogar.

En síntesis, el paisaje que se presenta aquí es el de una región volcada casi en su totalidad a las actividades agrícolas en la que habitan familias de campesinos asentadas en la región. Por sus características geográficas, sociodemográficas y productivas, estas regiones son fácilmente asimilables a otras regiones agrícolas como son Colonia, Santo Domingo de Soriano y Mercedes. La semejanza se encuentra, en primer lugar, en que son regiones que cuentan con un contingente importante de familias vinculadas a la pequeña producción. Según Gelman, a excepción de Soriano, se trataba de pequeños poblados donde residían pocas personas que vivían de la actividad agropecuaria. A diferencia de las regiones más cercanas a 
Montevideo, esta región dependía administrativamente de Buenos Aires; más aún, se la puede considerar como parte del hinterland más cercano a la capital virreinal no sólo por su ubicación geográfica y sus estrechas relaciones económicas, sino porque varios comerciantes porteños tendieron a instalar allí sus estancias más que en la campaña bonaerense.$^{38}$ Como las regiones cercanas a Montevideo, estas vivían de la actividad agropecuaria. Si bien la cría de ganado en esta región es más fuerte, la combinación con actividades de plantación de trigo y la cercanía a la capital virreinal hacen que el dinamismo de esta se asemeje al de las chacras y estancias que rodearon a Montevideo.

En segundo lugar, dentro del paisaje agrario del sur contamos con la variante de Minas. Esta región por estar más alejada de Montevideo presenta características diferentes a las ligadas a las actividades agrícolas. Si bien fue tradicionalmente ganadera y vinculada a la extracción de minerales, los datos muestran cierta complementación en las actividades agrícola y ganadera dejando atrás la idea de la ganadería como única actividad productiva.

$\mathrm{Al}$ igual que el paisaje anterior, este está compuesto también por familias asentadas en la zona con la variante de que buena parte de los jefes se declara como estanciero. Si bien esta región es notoriamente más ganadera que las anteriores, igualmente la mayor parte de la población vive en familias. La población de Minas urbano se muestra levemente feminizada, mientras que la parte rural es una población masculinizada. Esto se asocia al tipo de actividades que se realizaban en la zona rural.

El paisaje que se desprende de los padrones de Minas es de una población dedicada enteramente a la actividad primaria, donde a diferencia de las zonas más cercanas a Montevideo se combina el tipo de producción ganadera con la agrícola. El tipo de actividad que se realiza hace pensar que a medida que los terrenos se alejan de la villa de Minas las propiedades se vuelven más extensas. Estudios anteriores apuntan a que las unidades productivas que se registran en estos padrones no deben concebirse como enteramente monoproductoras. Una razón de esto es porque las condiciones técnicas de la época imponían cierta combinación de cultivos y cría de animales, asimismo, porque el grado de desarrollo tecnológico de los transportes no habilitaba la creación de áreas de localización productiva fuertemente especializada en regiones de poca densidad demográfica; finalmente porque la actividad ganadera de todo el paisaje sudatlántico implicó formas de producción diversas que van más allá de la forma clásica basada en la gran propiedad y en la cría extensiva. ${ }^{39}$

\footnotetext{
${ }^{38}$ Gelman, "Caminos", 1993, p. 90.

${ }^{39}$ Moraes y Pollero, "Categorías", 2010, pp. 31-32.
} 
Los estudios de microrregiones nos permiten tener una noción más específica de los paisajes y de la forma en la que se comportaba la población en las distintas localidades. En este caso nos referimos al sur de Uruguay, que si bien se le puede considerar como relativamente homogéneo, en el interior de este encontramos diferencias que están unidas a la forma en cómo se instalaron las poblaciones, la influencia que las guerras civiles ejercieron sobre estas, la proximidad o lejanía de la ciudad puerto y las trayectorias previas en materia productiva. Por la magnitud de los datos que se manejaron en este análisis estas diferencias no se analizaron con la profundidad que requeriría un análisis microrregional. Este tipo de estudios que complementan los ya realizados permitirán evaluar y complementar estos matices. Igualmente, debe tomarse en cuenta que se está analizando un periodo de 100 años y que estos paisajes son cambiantes. Este estudio capta solamente algunos de estos cambios así como ciertas permanencias que se mantienen con el correr del periodo.

Las características de la mano de obra y la estructura ocupacional: una aproximación a la evolución de estructura productiva en Montevideo, 1769-1858

a) La mano de obra. Este artículo analizó tanto la composición de la mano de obra como la estructura ocupacional. El primer análisis nos puede conducir a describir una determinada estructura social, mientras que el segundo aproxima a la estructura productiva.

En cuanto al primero, se realizó considerando la composición de los hogares, ya que se partió del supuesto de que una parte importante de la familia, principalmente en el medio rural, está vinculada con la actividad del jefe. Teniendo en cuenta los matices regionales en el apartado anterior, se puede decir que en la mayor parte del territorio sur de Uruguay se privilegió a la familia como unidad productiva, es decir, que la mano de obra libre superaba ampliamente a la mano de obra esclava y que la mayor parte de los trabajadores era propietaria de los medios de producción.

En la mayor parte del periodo analizado se presenta entonces una masa de población rural que controla los medios de producción, que está asentada en la tierra y que privilegia la mano de obra familiar sobre otras formas de relaciones laborales. Como ya se analizó, parece tratarse de una población de pequeños campesinos que combina en muchos casos la cría de animales con los cultivos, dependiendo esto de la región o localidad que se considere. Las zonas más cercanas a Montevideo están mayormente volcadas a las actividades agrícolas, mientras que las más alejadas, como en el caso de Minas, están mayormente dedicadas a la ganadería, pero con 
una proporción importante de labranza. Hacia el final del periodo puede verse un quiebre de esta tendencia ya que se equipara la proporción de personas registradas como productor o trabajador rural.

Según las características de los hogares analizados, la gran proporción de los jefes de hogar forma parte del grupo de los productores agrícolas, es decir, que ya fueran propietarios o arrendatarios una buena parte de los jefes de hogar controlaban los medios de producción. Por lo tanto, puede decirse que en la región estudiada la estructura social rural no se ajusta a la imagen de grandes propietarios que concentran la propiedad de los recursos productivos. Encontramos aquí en la mayor parte de los casos una población campesina pobre o de nivel medio que incorpora escasa mano de obra por fuera de la familia.

Otros estudios de la región se han encargado de aproximarse en términos de riqueza a las diferencias sociales dentro de estas poblaciones. Se ha constatado que no existen grandes diferencias entre estos productores y que el control de los recursos productivos parece haber sido el principal creador de diferencias sociales. ${ }^{40}$

b) La estructura ocupacional en Montevideo. Montevideo, por estar ubicada en una región estratégica y por contar con un puerto natural se benefició con el tráfico comercial de productos por el Atlántico. De las regiones analizadas es la que ha sido más estudiada, ya que fue por esta ciudad por la que entraron los primeros inmigrantes europeos, fue jurisdicción y centro administrativo del territorio de la Banda Oriental y en cierta medida fue debido a este puerto que la población y la economía se expandieron. Es decir, la ubicación territorial de la ciudad la define en términos de sus actividades, su población y sus redes con otros circuitos externos e internos.

Como otros puertos de la región, Montevideo se benefició mediante el comercio de productos y esclavos de la región y de los países de Europa. Esto la transformó en el periodo en una sociedad abierta a la recepción de extranjeros y móvil desde el punto de vista demográfico y social. En este trabajo se intentó realizar una aproximación a la estructura productiva de Montevideo ya que es donde se cuenta con la mayor cantidad de datos, lo que no sorprende por la importancia que tenía la ciudad en todo el periodo considerado y por ser esta también la más densamente poblada de las regiones analizadas. Asimismo, se intentó visualizar las características de la mano de obra.

Los datos que se manejaron no permiten visualizar el comportamiento real de la estructura productiva de la región. Las razones de esto son, en primer lugar, las características de la fuente, pues sólo permiten observar

${ }^{40}$ Moraes y Pollero, "Categorías”, 2010. 
la evolución de las actividades declaradas o el privilegio de una actividad sobre otra, pero no permiten determinar la estructura real. En segundo lugar, las ocupaciones son un indicador importante de la actividad económica, pero informan de manera solamente aproximada sobre la actividad real de una economía.

A partir de los datos, se puede ver una evolución aproximada del comportamiento de la estructura ocupacional en Montevideo. Al comienzo del periodo, 1769, se visualiza una primacía de la actividad agraria con un componente importante de la actividad ganadera. Desde el segundo padrón considerado la actividad primaria se vuelve muy poco significativa hasta el final del periodo. Las ocupaciones declaradas asociadas a esta están relacionadas al puerto, como la pesca. La desaparición de la actividad primaria en Montevideo se asocia más a la expansión de la ciudad y al consecutivo corrimiento de las zonas rurales hacia las afueras. En el comienzo del periodo se cuenta con el dato de toda la ciudad completa; igualmente en el casco se registra un porcentaje importante de actividad primaria que más adelante desaparece.

A partir del padrón de 1823 Montevideo comienza una progresiva diversificación de actividades. Ganan importancia más que nada los oficios artesanales ligados a materias primas como el cuero, la madera y el metal, entre otras. A su vez, el comercio se vuelve la actividad más declarada en todos los padrones exceptuando el primero. Hacia el final del periodo se constata también un crecimiento de los servicios.

Si bien es difícil hablar de un cambio estructural en el periodo que estamos considerando, se puede constatar a partir de los datos que en primer lugar el comercio aparece como actividad principal en la mayor parte del periodo analizado. Por tratarse de la ciudad portuaria se asume que gran parte de este se trataba del comercio atlántico. La red que este generaba en la ciudad puerto permitió probablemente incorporar personas con facilidad, por lo que, probablemente como lo estableció la historiografía tradicional, unas pocas personas sean las que se dedicaban al alto comercio, mientras que la mayoría se ocupa de actividades relacionadas al pequeño comercio aprovechando las externalidades que la anterior producía. Con los datos que nos brindan los padrones no es posible diferenciar esta cuestión.

En segundo lugar, en el correr del periodo se destacan las actividades relacionadas a los oficios. $\mathrm{Al}$ igual que con el comercio, pero en una medida de menor proporción estas actividades parecen ser la puerta de entrada para muchas personas que quieren realizar una actividad, debido a la forma que adoptan de maestro-aprendiz. Si bien esto no ha sido analizado profundamente en este trabajo, aparecen en los padrones numerosos casos de dependientes de personas ocupadas en oficios que declaran la 
ocupación del jefe de hogar. Esto convierte a Montevideo, más que nada en los años 1823 y 1836 en una ciudad con una presencia significativa de hogares desestructurados que giraban en torno a una actividad productiva. Asimismo, se constata hacia el final del periodo un crecimiento del sector servicios. Esto es coherente con la expansión de la población en la ciudad y con la cercanía del periodo a la modernización de la economía.

En síntesis, Montevideo se presenta en el correr del periodo como una ciudad que gira en torno al comercio de su puerto. Por la característica de buena parte de los hogares analizados (con alta presencia masculina en edad activa y en algunos casos desestructurados), Montevideo se presenta como una sociedad abierta a la recepción de inmigrantes. A excepción del padrón de 1769, esta ciudad presenta una abrumadora mayoría de comerciantes durante todo el periodo analizado. Hacia el final el aumento de los servicios y la diversificación ocupacional dan la pauta de la expansión de la población y de la economía en esta ciudad.

Finalmente, es indudable el peso que ejerció Montevideo en el sur de la región, como puerto de entrada de inmigrantes y como uno de los principales canales comerciales de la zona. Asimismo, constituyó para la historiografía una especie de punto cero desde donde se comenzó a poblar el territorio de Uruguay. Si bien esta relevancia es indiscutible, este estudio muestra paisajes diversos, que si bien muchos de estos giran en torno al puerto de la capital, también cuentan con cierta autonomía propia, una estructura demográfica específica que va acompañada de cierta especialización productiva. Lejos de pensar esta imagen como algo estático, se reconoce que esta va cambiando y que aquellas villas y poblados que en un comienzo se desempeñaron como el patio trasero de la capital, más adelante irán cobrando autonomía.

\section{FUENTES CONSULTADAS}

Archivos

AGN Archivo General de la Nación, Montevideo.

AGN-BA Archivo General de la Nación, Buenos Aires.

\section{Bibliografía}

Acevedo, Eduardo, Anales históricos del Uruguay, Montevideo, Barreiro y Ramos, 1933. 
Álvarez Lenzi, Ricardo y Otilia Muras, Área metropolitana de Montevideo y un núcleo dentro de ella: La Paz, Las Piedras. Antecedentes históricos, Montevideo, Facultad de Arquitectura-Instituto de Historia de la Arquitectura, 1977.

Apolant, Juan Alejandro, "Padrones olvidados de Montevideo del siglo XVIII", Boletín Histórico del Estado Mayor General del Ejército, 1967, núms. 112-115, Montevideo.

Barrán, José Pedro y Benjamín NAHum, Historia rural del Uruguay moderno, t. II: 18861884, Montevideo, Ediciones de la Banda Oriental, 1971.

, Historia rural del Uruguay moderno, t. IV: Historia social de las revoluciones de 1897 y 1904, Montevideo, Ediciones de la Banda Oriental, 1972.

, Historia rural del Uruguay moderno, t. III: 1895-1904, Montevideo, Ediciones de la Banda Oriental, 1973.

Historia rural del Uruguay moderno, t. v: La prosperidad frágil (1905-1914), Montevideo, Ediciones de la Banda Oriental, 1977.

Historia rural del Uruguay moderno, t. VI: La civilización ganadera bajo Batlle (1905-1914), Montevideo, Ediciones de la Banda Oriental, 1977.

, Historia rural del Uruguay moderno, t. VII: Agricultura, crédito y transporte bajo Batlle (1905-1914), Montevideo, Ediciones de la Banda Oriental, 1978.

Betancur, Arturo A., "La provisión de servicios en el puerto colonial de Montevideo: alcances y limitaciones de una fuente local de riqueza”, Anuario de Estudios Americanos, Escuela de Estudios Hispano-Americanos del Consejo Superior de Investigaciones Científicas, vol. LIII, núm. 2, 1996, pp. 123-145.

Congost, Rosa, Tierras, leyes, historia. Estudio sobre la "gran obra de la propiedad", Barcelona, Crítica, 2007.

Fradkin, Raúl y Juan Carlos Garavaglia (eds.), En busca de un tiempo perdido. La economía de Buenos Aires en el país de la abundancia 1750-1865, Buenos Aires, Prometeo Libros, 2004.

Frega, AnA, Pueblos y soberanía en la revolución artiguista. La región de Santo Domingo de Soriano desde fines de la colonia a la ocupación portuguesa, Montevideo, Ediciones Banda Oriental, 2007.

Garavaglia, Juan Carlos, Pastores y labradores de Buenos Aires. Una historia agraria de la campaña bonaerense 1700-1830, Buenos Aires, Ediciones de la Flor, 1999.

Gelman, Jorge, "Los caminos del mercado: campesinos, estancieros y pulperos en una región del Río de la Plata", Latin America Research Review, Latin American Studies Association, vol. 28, núm. 2, 1993, Pittsburg, pp. 89-118.

, Campesinos y estancieros. Una región del río de la Plata a fines de la época colonial, Buenos Aires, Editorial Los Libros del Riel, 1998.

y Daniel Santilli, "Distribución de la riqueza y crecimiento económico. Buenos Aires en la época de Rosas", Desarrollo Económico. Revista de Ciencias Sociales, Instituto de Desarrollo Económico y Social, vol. 43, núm. 169, 2003, pp. 75-101, Buenos Aires.

GonzÁlez Lebrero, Rodolfo, La pequeña aldea. Sociedad y economía en Buenos Aires (1580-1640), Buenos Aires, Biblos, 2002. 
Hettne, BJörn, Development Theory and the Three Worlds, Essex, Longman Scientific \& Technical, 1990.

Maeder, Ernesto J. A. y RAmón GutiérRez, Atlas histórico y urbano de la región del nordeste argentino. Pueblos de indios y misiones jesuíticas (siglos XVI-XX), Fundación MAPFRE América/Instituto de Investigaciones Geohistóricas-Consejo Nacional de Investigaciones Científicas y Técnicas, Chaco, 1994.

Millot, Julio y Magdalena Bertino, Historia económica del Uruguay, Montevideo, Ediciones de la Banda Oriental, 1991.

, Historia económica del Uruguay, Montevideo, Fundación de Cultura Universitaria, 1996, t. II.

Moraes, MarÍA InÉs, La pradera perdida. Una revisión de la historia agraria del Uruguay, 1700-1970, Montevideo, Linardi y Risso, 2008.

y RAQUel Pollero, "Formas familiares, estructura productiva y categorías ocupacionales en el Uruguay de la primera mitad del siglo XIX. Un estudio de caso: Canelones 1836" en Terceras Jornadas de Historia Económica de la Asociación Uruguaya de Historia Económica, Montevideo, 2003.

, "Categorías ocupacionales y estatus en una economía de orientación pastoril: Uruguay en la primera mitad del siglo XIX" en TARCÍsIO R. BOTELHO y MARCo H. D. VAn Leeuwen, Mobilidade social na América Latina em perspectiva histórica, Belo Horizonte, Editora da PUC Minas, 2010.

Pivel Devoto, Juan, Raíces coloniales de la revolución oriental de 1811, Montevideo, Editorial Medina, 1957.

Pollero, RAQUel, "Familia y fecundidad en el Uruguay. La inmigración en la conformación de la familia uruguaya. 1850-1908”, tesis de maestría en Estudios Migratorios, Uruguay, Facultad de Humanidades y Ciencias-Universidad de la República, 2001.

Ravignani, Emilio, Documentos para la historia argentina. Padrones de la ciudad y campaña de Buenos Aires (1726-1810), Buenos Aires, Peuser, 1920-1955, t. X.

Sala de Touron, Lucía et al., Evolución económica de la Banda Oriental, Montevideo, Ediciones Pueblos Unidos, 1967. y Rosita Alonso Eloy, Estructura económica y social de la colonia, Montevideo, Ediciones de la Banda Oriental, 1991. , El Uruguay comercial pastoril y caudillesco, Montevideo, Ediciones de la Banda Oriental, 1991.

Zubillaga Barrera, Carlos A., "Algunos antecedentes sobre el acondicionamiento territorial en Uruguay (1611-1911)" en Cuadernos del CLAEH, Centro Latinoamericano de Economía Humana, núm. 4, 1a. serie, 1977, pp. 37-61, Montevideo. 